\title{
Erratum to: Conservation genetics and genetic mating system of the yellow-shouldered blackbird (Agelaius xanthomus), an endangered island endemic
}

\author{
Irene A. Liu ${ }^{1}$
}

Published online: 20 June 2016

(C) Springer Science+Business Media Dordrecht 2016

\section{Erratum to: Conserv Genet (2015) 16:1041-1053 DOI 10.1007/s10592-015-0721-5}

In the original publication of the article, the data in the middle bar graphs of Fig. 1 showed total Shannon diversity over all loci, not Shannon diversity per locus as is more typically portrayed. To avoid confusion, the author has provided a modified figure in this erratum, in which Shannon diversity is divided by a factor of eight (the number of microsatellite loci used).

The online version of the original article can be found under doi: 10.1007/s10592-015-0721-5.

Irene A. Liu

irene.a.liu@gmail.com

1 Department of Biology, Duke University, Durham, NC 27708, USA 

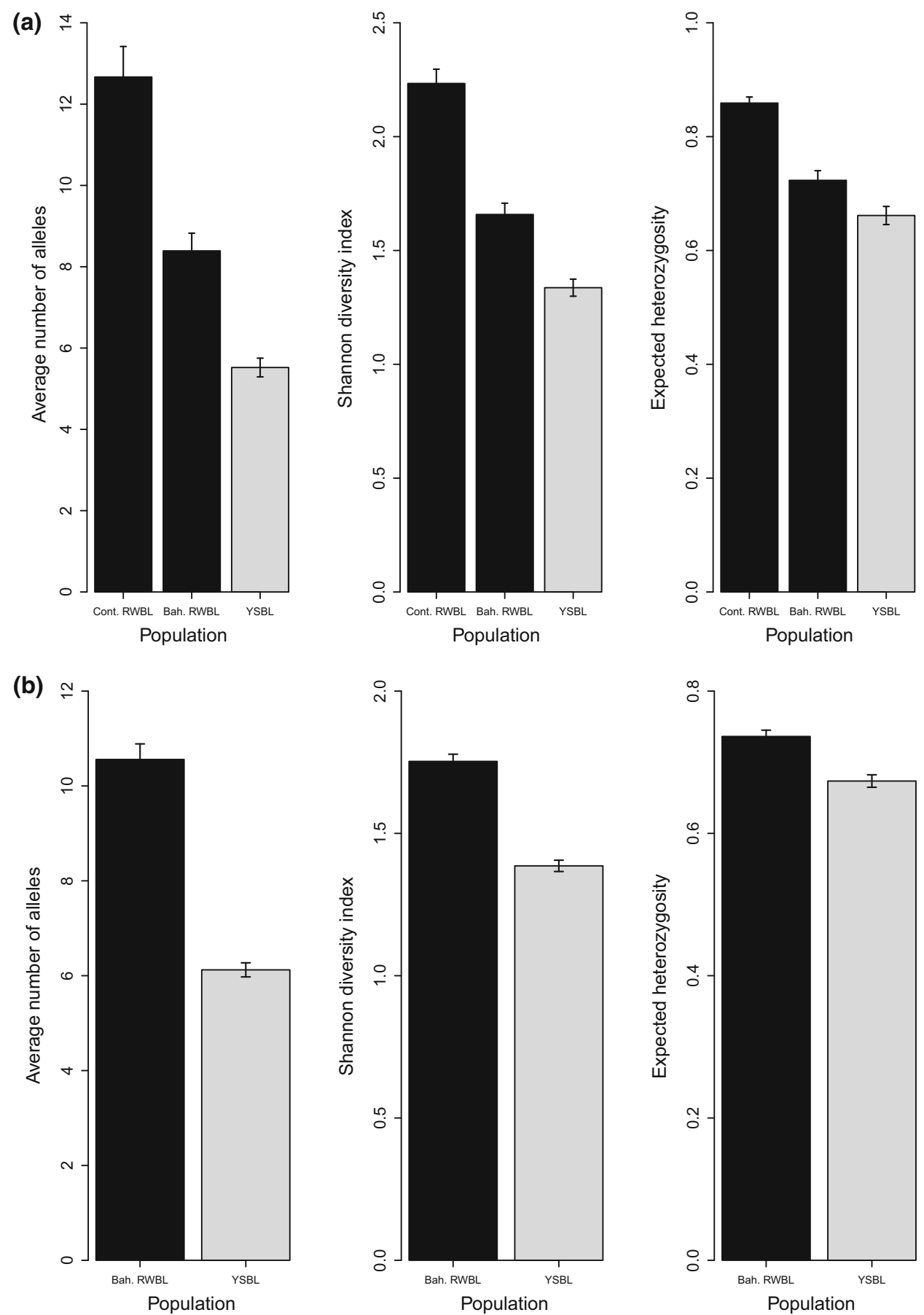

Fig. 1 Genetic diversity as measured by allelic diversity, Shannon diversity, and expected heterozygosity estimated from bootstrap simulations. a Comparison across six continental red-winged blackbird ("Cont. RWBL", black) populations, one island red-winged blackbird ("Bah. RWBL", black) population, and the yellow- shouldered blackbird ("YSBL", gray) population, with resample size of 20. b Comparison between Bahamas red-winged blackbirds and yellow-shouldered blackbirds, with resample size of 60 . The yellow-shouldered blackbirds have significantly less genetic diversity than both continental and island red-winged blackbird populations 